\title{
A Sustainability Lifecycle Assessment of Products and Services for the Extended Enterprise Evolution
}

\author{
Margherita Peruzzini, Michele Germani, and Eugenia Marilungo \\ Università Politecnica delle Marche, via Brecce Bianche 12, 60131 Ancona \\ \{m.peruzzini,m.germani, e.marilungo\}@univpm. it
}

\begin{abstract}
Recently numerous companies are moving from products to services to create new business opportunities and increase the value perceived by the customers thanks to an extended value creation network. The research challenge is to support traditional manufacturing enterprises evaluating the shift from products to services as far as sustainability is concerned. While product sustainability can be assessed by several tools, the impacts of PSS (Product-Service Systems) are almost unexplored. This paper adopts a holistic approach to assess sustainability by estimating three main impacts: environmental, economical and social. The methodology is illustrated by means of an industrial case study focusing on washing machines; it analyses the traditional scenario based on tangible product selling with a vertical supply-chain, and an innovative PSS scenario proposing washing as a service within an extended network. Data comparison highlights the achievable benefits of PSS on sustainability.
\end{abstract}

Keywords: Sustainability, Lifecycle Design, Extended Enterprise, PSS (ProductService System).

\section{Introduction}

Numerous manufacturing enterprises are challenged by the transition from a traditional product-oriented model to a new extended service-oriented one, which can be realized by Product-Service Systems (PSS) [1]. This trend mainly consists of adding a wide range of services to increase the value perceived by the customers and better satisfy their needs. In manufacturing industry, PSS are almost realized by technical services (e.g. maintenance, user training, retrofitting and product monitoring, etc.). They usually imply high cost reduction, new market potentials and higher profit margins, and they can significantly influence performances and sustainability. In order to achieve these benefits with low impact, PSS require creating new relationships between different stakeholders to fully exploit the virtual enterprise capabilities. As a consequence, the interrelations between products and non-physical services are complex to model: different lifecycles must be adopted and properly indicators considered.

In this context, the research aims to support the extended enterprise in PSS ideation and design embracing sustainability principles. The paper proposes a methodology for a holistic assessment of both manufacturing product and technical services according 
to main sustainability factors. It combines LifeCycle Assessment (LCA), LifeCycle Costing (LCC) and Social LifeCycle Assessment (SLCA), and finally obtains a unique Sustainability Assessment value (SA). Such an analysis can be carried out until the preliminary design stages in order to envisage the environmental, economical and social impacts of different solutions; impacts can be analysed separately or in a global way. The method validity is demonstrated by an industrial case study focusing on washing machines, which compares the sustainability of traditional product (where washing machine is sold as usual) and PSS (where the user only pays for the washing cycles as a service).

\section{Background on PSS and Sustainability Performance}

Although the existing numerous definitions, it's possible to gather some common aspects of services [2]. A product-service consists of proposing a mix of tangible products and intangible services designed and combined to increase the value for customers [3]. Value creation can be provided through an extended business network involving different stakeholders, which concur to create the services. Product-service idea starts from the concept of extended product [4], where intangible services are incorporated into a core product to add value. In particular, Product+Service refers to a contemporary offer of product and services, while Product2Service refers to selling only the services. The term PSS usually includes the tangible product, the related services, the enterprise network and the infrastructures needed [5]. In manufacturing applications PSS are almost based on technical services [6]. Technical services are characterized by: supporting the product use, having a concurrent lifetime to the product to which they relate, and interacting with the customers. Technical services offer some advantages from manufacturers: low-cost, quick diversification, creation of wider market offer, shorter time-to-market, and higher sustainability [7].

Sustainability is nowadays accepted as a guiding principle for achieving highly competitive solutions and creating added value. Actually, the modern sustainability thinking considers three dimensions: environment, economy, and social wellbeing [8]. From the economical viewpoint, services can create new market potentials and higher profit margins, and can contribute to higher productivity by means of reduced investment costs along the lifetime as well as reduced operating costs for the final users [9]. From an ecological viewpoint, product-services can be more efficient thanks to a more conscious product usage, an increased resource productivity and a close loop-chain manufacturing as reported by some examples $[9,10]$. Finally, PSS can be also socially advanced, as services are able to build up and secure knowledge intensive jobs and can contribute to a more geographically balanced wellbeing distribution [11]. However, the biggest challenge is carrying out a reliable sustainability assessment for PSS.

As far as product sustainability is concerned, it has been demonstrated that lifecycle approaches offer a structured methodology to proceed with comparative analysis [12]. LifeCycle Assessment (LCA) and LifeCycle Costing (LCC) enable the achievement of eco-efficiency solutions [10,13], while SLCA can estimate the social impact in terms of Quality Adjusted Life Years $[14,15]$. Nevertheless they are generally applied to physical products. 
About service analysis, several methods have been recently proposed to manage PSS (from modularization-focused approach, to stochastic and behaviour-focused approach, until lifecycle-focused methods) [16]. However, some of them are very theoretical and hard to implement in practice, while others are too specific and have a limited applicability. None of them provide a concrete sustainability evaluation to be applied in manufacturing cases on both PSS and traditional products.

\section{$3 \quad$ Methodology for an Integrated Sustainability Assessment}

The proposed methodology is based on lifecycle modelling and analysis to measure environmental, economical and social impacts, and finally perform a global Sustainability Assessment (SA) by coupling separated analysis. Such an approach has three main advantages: it well address technical services as it exploits the lifecycle approach; it can be adopted until the preliminary design stages to support decisionmaking and objectively compare and validate the technicians' choices; and it can be easily applied to both product and services to compare alternative scenarios, evaluating the consumed resources and choosing the solution with the lower impact. Furthermore, it adopts the basic concepts of the benchmarking methods: defining reliable metrics to assess and compare different design solutions. Such an approach has been already used for other purposes [17-18], but not for product-services.

The method steps are:

Step 1. Lifecycle modelling: it is based on a detailed functional analysis and the assessment of all the systems/subsystems at different lifecycle stages. Modelling comprehends the core product, the technological infrastructure and the services. Products are modelled according to LifeCycle Design (LCD) approaches, so the main stages are: ideation, design, manufacturing, use, and end-of-life. Services modelling follows the ISO 15704 (2000) suggestions and considers the following main stages: ideation, design, implementation, operation and final disposal;

Step 2. Use scenario definition: it consists of identifying the user profiles, describing the users' behaviours and defining the lifetime to be considered;

Step 3. Lifecycle analysis: each system is analysed separately by LCA, LCC and SLCA to find out the separated impacts. Analyses are fully consistent as they share the same product/service model, but each of them focuses on different aspects: LCA on environmental resources and ecosystem, LCC on total costs by considering the company, the consumer and the dismissing consortium viewpoints, and SLCA on human resources and human health. Step 3 is described in more details in section 3.1;

Step 4. Global sustainability assessment (SA): for each analysed scenario, the three calculated indexes are normalized and then summed to obtain a unique assessing value SA:

$$
L C A+L C C+S L C A=S A
$$

Step 4 is fully explained in section 3.2.

The proposed methodology is schematized in Figure 1. Product and PSS analyses run in parallel and converge in some points. Sustainability assessment focuses only on the operative phases; indeed, the impacts of ideation and design stages is limited and 
they are similar for product and PSS, so they can be neglected. The method procedure is pragmatic and can be straightforwardly carried out in different manufacturing contexts, since data can be easily inferred investigating product/service BOM (Bill Of Material), production documents, use data and disposal practices. Such method extends a recent work about PSS where the analysis lacked of normalization [10]. It can be also implemented by a collaborative platform supporting an extended enterprise [19] to evolve the network from product to services.

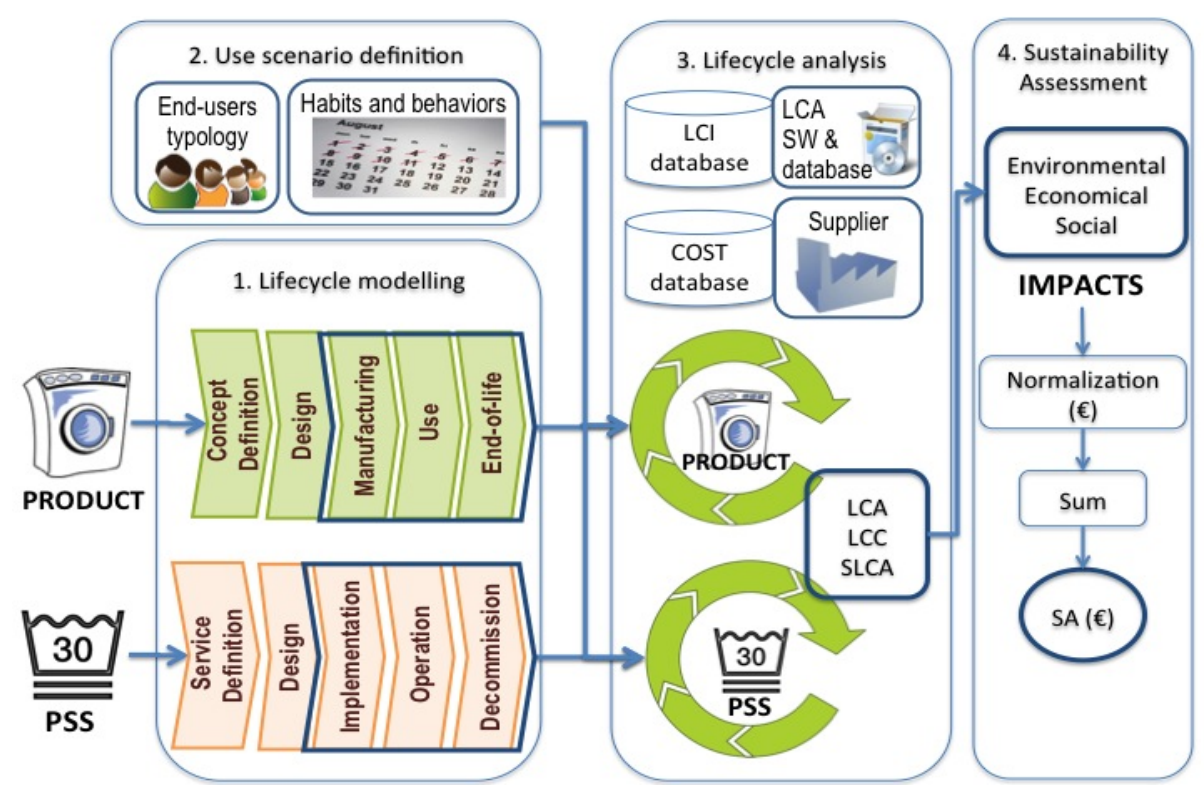

Fig. 1. Methodology for Product and PSS sustainability assessment

\subsection{Lifecycle Analysis and Sustainability Impacts}

The lifecycle analysis considers all significant data referring to the analysed phases for product (Manufacturing, Use, End-of-life) and service (Implementation, Operation, Decommission). The analysis follows LCA approach [13]. Firstly, all data about raw materials extraction, processing, assembling and transportation as well as the use and operational data and the end-of-life information need to be collected according to the functional model of each specific case. Then, the impacts are estimated for each lifecycle phase and a global value is defined. Such an approach allows comparing different alternative cases by considering the global impact; the comparison can be also focused on a specific identified phase.

The environmental impact is calculated by LCA Eco-Indicator99 (EI-99) methodology [20], considering Ecosystem Quality impact and Resources consumption. The $<$ unit of measurement is EI-99 point $(\mathrm{Pt})$. 
The economical evaluation considers the same functional model and adopts the Equivalent Annual Cash Flow technique (EA) to transform a generic cash flow distribution into an equivalent annual distribution by cost actualization according to (1):

$$
E A=P \frac{(i+1)^{n_{* i}}}{(i+1)^{n}-1}
$$

where $n$ is the lifetime years' number, $i$ is the generic discount rate (for example $3 \%$ ), and $P$ is the value during the all lifetime. The obtained cost impact considers all system costs: during manufacturing and implementation phases the costs relate to company or extended enterprise expense, during use and operation cost refer to the consumer, and during end-of-life and decommission charge the dismissing consortium and involved entities. The impact is expressed in Euro.

The social impact considers separately Human Health contributions according to LCA Eco-Indicator99 (EI-99) methodology as before. Impact is expressed into QALYs (Quality Adjusted Life Years). Such values can be calculated by creating ad hoc analyses with the support of LCA and LCC software tools (i.e. SimaPro, Gabi, Relex).

\subsection{Global Sustainability Assessment by Normalization}

All the three analyses are coherent with the same functional model; it assures that the obtained results can be coupled to find a unique sustainability index. However, each analysis has a different unit of measurements (i.e. EI-99 Pt, Euro, QALYs). Data normalization allows translating the obtained impact values into Euro and calculating a unique monetary value called Sustainability Assessment (SA). It expresses how each analysed solution affects the overall sustainability. Higher is the impact, and lower is the sustainability. The normalization procedure adopted in the proposed method is described in Table 1. The adopted formulas are based on European average data for having a consistent redefinition.

Table 1. Normalization procedure

\begin{tabular}{|l|c|c|c|}
\hline $\begin{array}{l}\text { IMPACT } \\
\text { CATEGORY }\end{array}$ & $\begin{array}{c}\text { Original } \\
\text { meas. unit }\end{array}$ & Normalization formulas & $\begin{array}{c}\text { Normalized } \\
\text { meas. unit }\end{array}$ \\
\hline $\begin{array}{l}\text { Environmental } \\
\text { Impact }\end{array}$ & EI-99 Pt & $\begin{array}{c}\text { Pt }->\mathrm{PDFm} 2 \mathrm{yr}->(P D F m 2 y r) * 1,4=\text { Euro } \\
\mathrm{Pt}->\mathrm{MJ}->M J * \frac{0,00411}{\text { lifetime }}=\text { Euro }\end{array}$ & Euro \\
\hline $\begin{array}{l}\text { Economical } \\
\text { Impact }\end{array}$ & Euro & - & Euro \\
\hline Social Impact & QALY & 1 QALYs $* 74.000=$ Euro & Euro \\
\hline
\end{tabular}

PDFm2yr = Potentially Disappeared Fraction of species per square meter per year, $M J=$ Mega Joule, QALYs = Quality Adjusted Life Years 


\section{Industrial Case Study: Washing as a Service}

\subsection{Product and PSS Case Studies}

The case study has been realized in collaboration with an Italian company producing household appliances and home care device. The company is actually organized in a vertical supply-chain and adopts a product-oriented development process. Collaboration with partners and suppliers is limited to design innovation and reduction of production time and cost. The case study focuses on washing machine product (WM) and its evolution towards the creating of a new PSS to better satisfy the market needs.

The product case study considers the tangible good as an assembly of numerous components, which enables washing clothes. The consumer pays the product at the beginning (about 460,00 €) and than pays for the consumed resources (clean water, electric energy and detergents) according to a traditional model. The PSS case study refers to selling a Product2Service solution where the customer pays only for the service while the WM is given for free. The user pays a service rate consisting of two parts: a "payXuse" fee at each washing cycle effectively done $(0,45 € /$ cycle) and a discounted rate for the consumed resources (water and energy) fixed in collaboration with the energy suppliers. Compared to the traditional case, the product is enhanced with some additional components able to connect the WM to Internet and allow remote monitoring. Furthermore, the ecosystem is more complex as it is made up of multiple partners: the producer company, the energy supplier, the water supplier, a service provider who is responsible for service activation and delivery, and some local technical partners, which deliver the WM at home and control its status.

\subsection{User Profile and Use Scenarios}

For both Product and PSS cases, three scenarios are investigated. They consider the most representative European lifestyle according to a recent market analysis carried out by the producer company's marketing department. The identified user profiles are:

- House Manager (HM): it is an expert user, generally a woman, spending a lot of time at home (e.g. housewife or retired), who takes care house management and family issues in a special way. HM is characterized by a medium number of cycle per week (4,3 cycles/week) with optimized loading;

- Efficiency Seeker (ES): it is a user, generally a senior man or a young woman, with an active social life and an efficient, fast and pragmatic house management. ES is characterized by an high number of cycle per week (5,8 cycles/week) with low loading;

- Delegator (D): it is a young user, girl or boy, who pays a limited attention to the house care in general due to an intense workload or other causes. D is characterized by a limited number of cycles per week ( 3,9 cycles/week) with medium/high loading. 
The use scenarios considers the three user profiles according to the average number of cycle per week and a variable lifetime that varies from 1 to 10 years, for both product and PSS.

\subsection{Product and PSS Sustainability Assessment}

The proposed method (see Fig. 1) is applied to compare the different use scenarios for both product and PSS designed solutions.

As far as traditional product is concerned, the Manufacturing phase analysis considers all the components used for production and assembly, and data are organized according to the main product functional entities (e.g. oscillating group, balancing and suspensions, electrical components, hydraulics, aesthetics, cabinet). A 5\% cut-off is applied to neglect those parts that have a limited impact. The Use phase analysis considers the habits of the investigated user profiles (HM, ES, D) during the lifetime (1-10 years). As suggested by real data monitoring and statistical data from the producer company's technical departments, a realistic decrease of the washing machine performance corresponding to efficiency losses is estimated. Performance decrease is expressed by a cut percentage according to the number of the executed cycles $(5 \%$ reduction after 500 cycles, $10 \%$ reduction after 1000 cycles, $20 \%$ reduction over 2000 cycles). Costs are generated by resource consumptions and are considered with the relative prices: electric energy $(0,2 € / \mathrm{kWh})$, water $(0,0011 € / \mathrm{lt})$, detergents $(2,5 € / \mathrm{lt})$, softener $(1,4 € / \mathrm{lt})$, calcium remover $(0,33 € /$ cycle $)$. In the End-of-Life phase analysis, LCA follows European Directive on Electric Equipment Waste (WEEE) for managing the product components, which indicate the percentage for recycling (55\%), reuse $(10 \%)$ and landfill $(35 \%)$.

As far as the PSS assessment is concerned, the Implementation phase analysis considers product as well as the product analysis, but comprehends also the additional components and the system infrastructure. The approach is similar to the product scenario. Furthermore, a new cost item is represented by the "service expense", which considers the call-centre services, the personnel employed there and the wiring network. The Operation phase analysis considers higher performances due to a continuous control of the machine status and real-time monitoring and assistance (i.e. PSS machine is monitored and parts can be substituted in advance to guarantee a high quality performance for the entire lifetime). The Decommission phase analysis differs from product because the manufacturer directly manages product disposal and the extended enterprise manages the service decommission. Data about percentage of recycling, reuse and landfill are taken from the producer company and the dismantling consortium.

\subsection{Results and Comparative Analysis}

Table 2 shows the obtained results for both product and PSS, focusing on a 10-year lifetime. It contains the values derived from the separated analysis as well as the global Sustainability Assessment (SA), which is calculated after normalization. For each user profile, SA expresses the total impact as it sums all the contributions. It is worth to notice that, for a period of 10 years, PSS is more convenient for any user profile, regardless to the user habits. Furthermore, data can be investigated also over the years to better understand whether and how PSS advantages evolve during the lifetime. 
Table 2. Lifecycle analysis results (LCA + LCC + SLCA)

\begin{tabular}{|l|c|c|c|c|c|c|}
\hline & \multicolumn{3}{|c|}{ PRODUCT } & \multicolumn{3}{c|}{ PSS } \\
\hline 10-years lifetime & HM & ES & D & HM & ES & D \\
\hline Env. Impact $(\mathrm{Pt})$ & $6,00 \mathrm{E}+02$ & $7,72 \mathrm{E}+02$ & $6,44 \mathrm{E}+02$ & $4,57 \mathrm{E}+02$ & $6,08 \mathrm{E}+02$ & $5,02 \mathrm{E}+02$ \\
\hline Eco. Impact $(€)$ & $€ 5.994,32$ & $€ 6.688,50$ & $€ 6.071,67$ & $€ 4.544,01$ & $€ 5.577,53$ & $€ 4.513,08$ \\
\hline Soc. Impact $(\mathrm{QALY})$ & $1,00 \mathrm{E}-02$ & $1,29 \mathrm{E}-02$ & $1,05 \mathrm{E}-02$ & $6,64 \mathrm{E}-03$ & $9,14 \mathrm{E}-03$ & $7,09 \mathrm{E}-03$ \\
\hline GLOBAL SA $(\boldsymbol{€})$ & $\mathbf{€ 6 . 8 4 9 , 9 9}$ & $€ \mathbf{7 . 7 7 2 , 9 5}$ & $\mathbf{€ 6 . 9 5 5 , 6 5}$ & $\mathbf{€ 5 . 1 1 8 , 8 0}$ & $\mathbf{6 . 3 5 5 , 9 0}$ & $€ \mathbf{5 . 1 2 0 , 0 2}$ \\
\hline
\end{tabular}

Figure 2 shows the SA trend over the years in respect with the user classes: the product impact is constantly higher, but ES users are more charged. Services have always less impact, even if the advantages are greater along in years. Moreover, PSS is particularly good for HM and D users, especially after 5 years. Interesting analyses can be also carried out about some specific aspects: indexes can be separately mapped over the years to compare product and PSS relatively to one specific contribution.

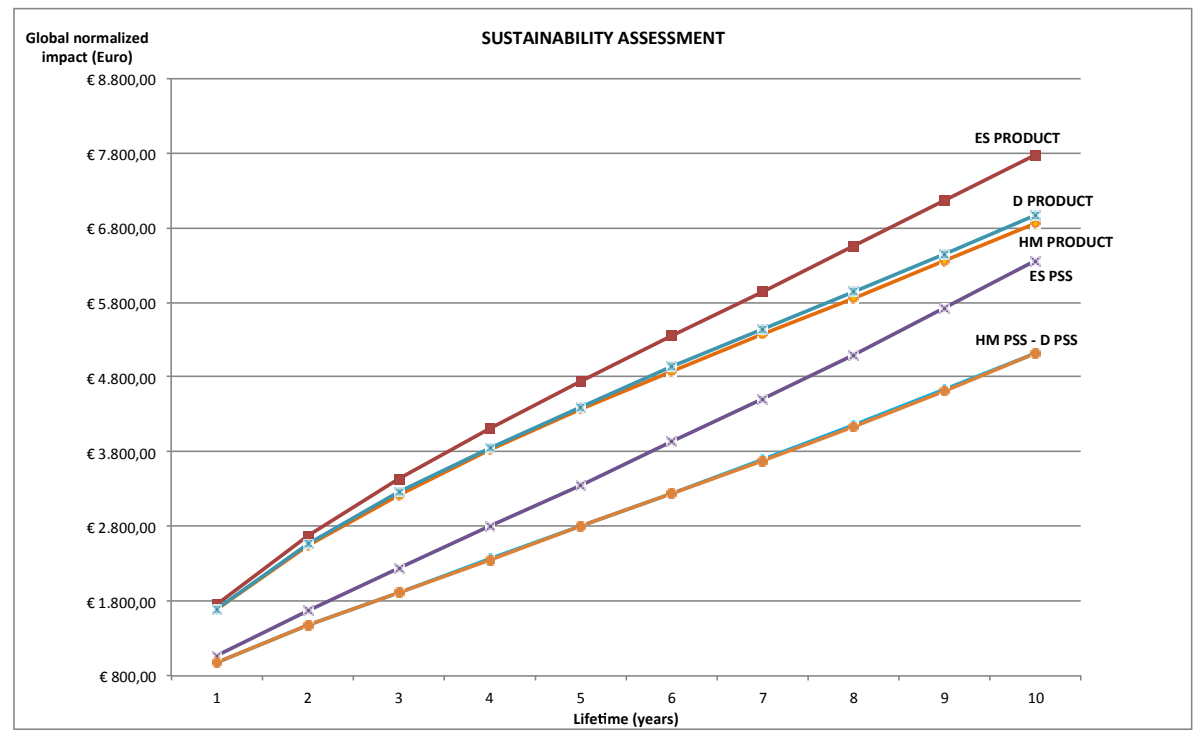

Fig. 2. Global Sustainability assessment over the years (normalized value)

Finally, figure 3 shows the cost analysis along 10-years lifetime, considering both the company expenses and the consumer rates. Company costs are lower than the consumer ones and slightly in growth in both cases; finally, PSS is marginally more expensive. Contrariwise, the consumer perspective is very interesting: washing as a service is always cheaper than traditional product and the benefits for consumers are greater and steady in growth over the years. 


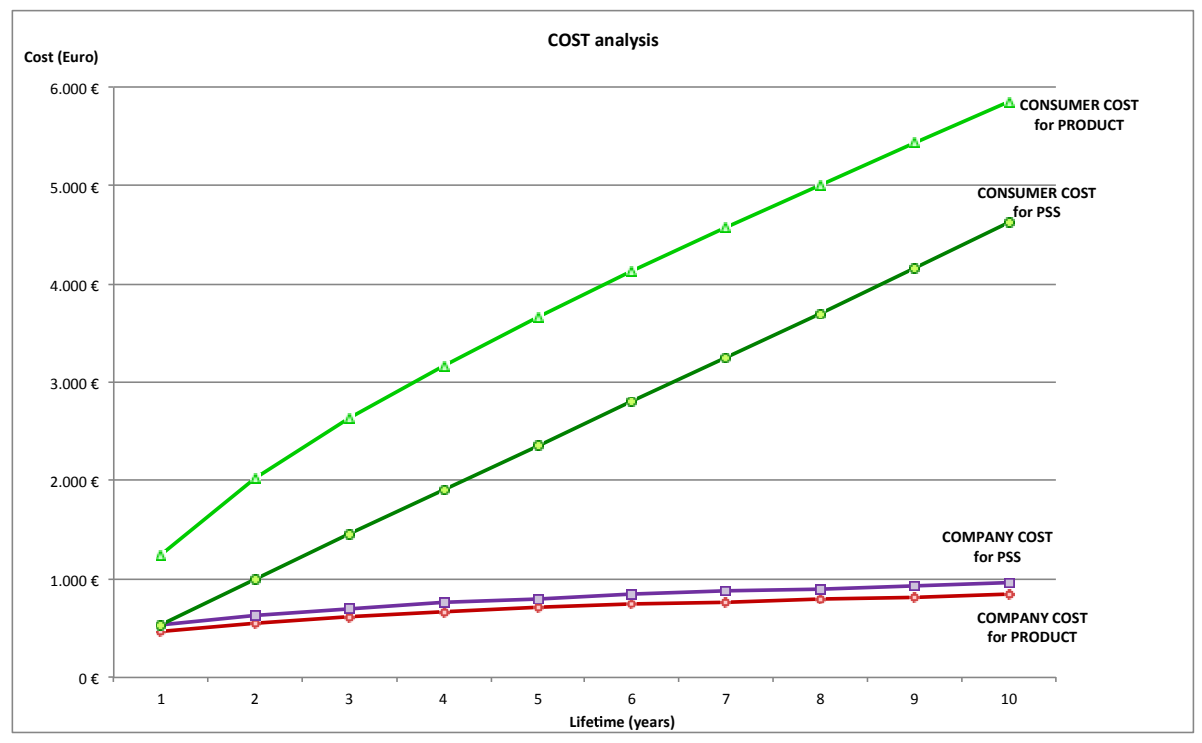

Fig. 3. Comparative cost analysis (company cost and consumer expense during the lifetime)

\section{Conclusions}

The paper proposes a methodology to assess PSS sustainability and compare with traditional product solutions. The method validity is demonstrated by an experimental case study focusing on washing as a service and exploring the benefits in respect with the traditional product. Both scenarios are modelled according to lifecycle design approaches and investigated in terms of environmental, economic and social impacts. Experimentation demonstrates the reliability of such a method to easily assess sustainability of both products and services and compare different organizational assets. The paper extends the latest research in product-service and proposes a concrete application of a sustainability assessment method to support decision-making during the design or optimization phases within the extended enterprise.

\section{References}

1. Goedkoop, M.J., Van Halen, C.J.G., Riele, H.R.M., Rommens, P.J.M.: Product-Service Systems - Ecological and Economic Basic. PWC, The Hague (1999)

2. Balin, S., Giard, V.: A process oriented approach to service concepts. In: 8ème Conférence Internationale de Génie Industriel, Tarbes, France (2009)

3. Furrer, O.: Le rôle stratégique des "services autour des produits". Revue Française de Gestion (113), 98-108 (2007)

4. Thoben, K.D., Jagdev, H., Eschenbaecher, J.: Extended Products: Evolving Traditional Product Concepts. In: Proc. 7th International Conference on Concurrent Enterprising, Bremen (2001) 
5. SUSPRONET final report: http: / /www. suspronet.org/

6. Mont, O.K.: Clarifying the concept of Product-Service System. Journal of Cleaner Production 10(3), 237-245 (2002)

7. Aurich, J.C., Fuchs, C., Wagenknecht, C.: Life Cycle oriented design of technical ProductService Systems. Journal of Cleaner Production 14, 1480-1494 (2006)

8. Adams, W.M.: The Future of Sustainability: Re-thinking Environment and Development in the Twenty-first Century. Report of the IUCN Renowned Thinkers Meeting (2006)

9. Baines, T.S., Lightfoot, H., Evans, S., Neely, A., Greenough, R., Peppard, J., Roy, R., Shehab, E., Braganza, A., Tiwari, A., Alcock, J.R., Angus, J.P., Bastl, M., Cousens, A., Irving, P., Johnson, M., Kingston, J., Lockett, H., Martinez, V., Michele, P., Tranfield, D., Walton, I.M., Wilson, H.: State of the art in Product-Service System. Journal of Engineering Manufacture 221, 1543-1552 (2007)

10. Favi, C., Peruzzini, M., Germani, M.: A lifecycle design approach to analyse the ecosustainability of industrial products and product-service systems. In: Marjanovic, Storga, Pavkovic, Bojcetic (eds.) Proc. of International Design Conference DESIGN 2012, pp. 879-888 (2012)

11. Stahel, W.: The Utilization-Focused Service Economy, Resource Efficiency and ProductLife Extension. In: Allenby, B., Richard, D. (eds.) The Greening of Industrial Ecosystem, pp. 178-190. National Academy Press, Washington, DC (1994)

12. Jeswiet, J.: A definition for life cycle engineering. In: Proc. 36th International Seminar on Manufacturing Systems, Saarbrucken, Germany (2003)

13. ISO 14040, Environmental Management - Life Cycle Assessment - Principles and Framework (2006), ISO 14044, Environmental Management - Life Cycle Assessment - Requirements and Guidelines (2006)

14. Weidema, B.: The integration of economic and social aspects in life cycle impact assessment. Int. J. Life Cycle Assess. 11(1), 89-96 (2006)

15. Norris, G.A.: Integrating Life Cycle Cost Analysis and LCA. Int. J. LCA Assess. 6(2), $118-120$ (2001)

16. Garetti, M., Rosa, P., Terzi, S.: Life Cycle Simulation for the design of Product-Service Systems. Computers in Industry 63, 361-369 (2012)

17. Germani, M., Mengoni, M., Peruzzini, M.: Metrics-based Approach for VR Technology Evaluation in Styling Product Design. In: ASME 2009 International Design Engineering Technical Conferences \& Computers and Information in Engineering Conference, DETC/CIE (2009)

18. Germani, M., Mengoni, M., Peruzzini, M.: A benchmarking method to investigate codesign virtual environments for enhancing industrial collaboration. In: ASME World Conference on Innovative VR 2010 (2010)

19. Germani, M., Mandolini, M., Mengoni, M., Peruzzini, M.: Collaborative design system for supporting dynamic virtual enterprises. In: Camarinha-Matos, L.M., Boucher, X., Afsarmanesh, H. (eds.) PRO-VE 2010. IFIP AICT, vol. 336, pp. 577-584. Springer, Heidelberg (2010)

20. Goedkoop, M., Effting, S., Collignon, M.: The Eco-indicator 99 - A damage oriented method for Life Cycle Impact Assessment. Manual for Designers, 2nd edn. (2000) 